\title{
De novo postmenopausal endometriosis during tibolone treatment: a case report and review of the literature
}

\author{
Berna Dilbaz • Yesim Bayoglu Tekin • Serdar Dilbaz • \\ Ali Haberal
}

Received: 29 August 2007 / Accepted: 15 October 2007 / Published online: 30 November 2007

(C) Springer-Verlag 2007

\begin{abstract}
Endometriosis is uncommon before puberty and after menopause as it is an estrogen-dependent disease. A case is presented of postmenopausal endometriosis encountered in a patient who had received tibolone (Livial, Organon, Cambridge, UK) 1 year before the diagnosis of the adnexal mass for 3 months for relief from vasomotor symptoms and had the medication stopped because of fibrocystic disease of the breast. Transvaginal ultrasonography showed homogeneous cystic adnexal mass of $36 \times 26 \mathrm{~mm}$ with no internal echoes in the right ovary. Laparoscopic right salpingooophorectomy was performed and the histopathological examination of the cyst showed an endometriotic cyst. Most of the cases with postmenopausal endometriosis are associated with the use of hormone replacement therapy (HRT). However, tibolone is recommended in hormone replacement therapy of postmenopausal symptomatic women who have a past history of hormone-dependent tumors such as endometriosis. There is restricted data in the literature about tibolone use and recurrence or de novo formation of endometriosis.
\end{abstract}

Keywords Postmenopausal endometriosis · Tibolone · HRT

\section{Introduction}

Endometriosis is defined as the growth of endometrial tissue outside the uterus. This condition is an estrogen-

B. Dilbaz $\cdot$ Y. B. Tekin $\cdot$ S. Dilbaz $\cdot$ A. Haberal

Obstetrics and Gynecology, Ministry of Health Ankara,

Etlik Maternity and Women's Health Teaching and Research Hospital,

Etlik, Ankara, Turkey

S. Dilbaz $(\bowtie)$

Mithatpasa Caddesi 59/3,

06420 Kizılay, Ankara, Turkey

e-mail: sdilbaz@hotmail.com dependent disease and occurs in approximately $10 \%$ of the women of reproductive age [1]. Endometriosis is uncommon before puberty and after menopause [2].

Indeed the lesions regress after menopause or ovariectomy. Women who were diagnosed to have endometriosis in the postmenopausal period are estimated to be only $2-4 \%$ of the disease population [3]. Postmenopausal endometriosis can occur with a wide spectrum of symptoms besides the presence of asymptomatic masses including abdominal pain, bleeding and intestinal or urinary tract obstruction [4]. We report a case of postmenopausal de novo endometriosis after use of tibolone in a patient with no past history of endometriosis or adnexal mass.

\section{Case report}

A 56-year-old woman, gravida 3, para 3, body mass index $26 \mathrm{~kg} / \mathrm{m}^{2}$ presented with ongoing pelvic pain for the last year. She had not experienced infertility, dysmenorrhea, or dyspareunia during her reproductive years. Her three pregnancies resulted in normal vaginal deliveries at term. She had regular flow until hypermenorrhea occurred in the premenopausal period; menopause ensued at 51 years of age. For the last 5 years she had attended the Menopause Clinic for follow-up visits, and annual physical examination, pelvic sonography, and cervical smear screening carried out as a part of a routine protocol revealed no pathological findings.

One year before the diagnosis of the adnexal mass, she had received tibolone (Livial, Organon, Cambridge, UK) for 3 months for relief from vasomotor symptoms, but the medication was discontinued because of fibrocystic disease of the breast. She was taking antihypertensive drugs at the time. A fullness presumed to be a right adnexal mass was 
palpated during bimanual vaginal examination. She was referred to the Endoscopic Surgery Unit. Transvaginal ultrasonography showed a homogeneous cystic adnexal mass of $36 \times 26 \mathrm{~mm}$ with no internal echoes in the right ovary and an endometrial thickness of $10 \mathrm{~mm}$ was measured.

A saline sonohysterography was performed showing a submucous leiomyoma of $17 \times 15 \mathrm{~mm}$. Serum concentrations of the tumor markers were as follows: CA-125= $12.3 \mathrm{U} / \mathrm{ml}$, CA $19-9=41.82 \mathrm{U} / \mathrm{ml}$. Laparoscopy and hysteroscopy were performed on May 2007. During observation of the peritoneal cavity, a $5-\mathrm{cm}$ right ovarian cyst adherent to the fossae ovarica and the posterior wall of the uterus was observed; otherwise the pelvic and peritoneal cavity was normal. After taking peritoneal washings for cytological examination, right salpingooophorectomy was performed in addition to hysteroscopic resection of the submucous leiomyoma $2.5 \mathrm{~cm}$ diameter that was located at the left cornual side. The histopathological examination of the cyst showed an endometriotic cyst.

\section{Discussion}

Endometriosis is commonly a disease of the reproductive ages associated with pelvic pain, dysmenorrhea, and infertility. As endometriosis is an estrogen-dependent disease, it is rarely seen after menopause. Most of the cases of postmenopausal endometriosis are associated with use of HRT, and the majority of the recent reports were cases with known endometriosis that recurred in the postmenopausal period after estrogen replacement therapy.

The recurrent disease is more severe than the primary disease in some cases [5-9]. However, HRT has been reported to be associated with development of de novo endometriosis in a hysterectomized postmenopausal patient [10]. A case of cutaneous endometriosis was reported in a postmenopausal woman receiving hormonal replacement, highlighting the possibility of growth of extrauterine endometrial tissue during exposure to exogenous estrogen [11].

Tibolone [(7,17_)-17-hydroxy-7-methyl-19-norpropen5(10)-en-20-yn-3-one] is a steroid that exhibits weak estrogenic, progestogenic, and androgenic activity and has been shown to have a beneficial effect on climacteric vasomotor symptoms and on depressed mood [12]. Combined estrogenic, androgenic, and progestogenic activities exert a positive synergistic effect on certain target organs, e.g., the hypothalamic-pituitary axis, and antagonistic or complementary effects on others, e.g., endometrium. The effect of tibolone on endometrium is inhibitory as progestogenicandrogenic activity is dominant. Tibolone, being a non-bleeding form of hormone replacement therapy, is recommended in postmenopausal symptomatic women who had hormonedependent tumors such as endometriosis in the past [13]. The drug is used to treat the vasomotor symptoms of women with endometriosis, as it is presumed to show minimal stimulative effect on ectopic endometrial tissue [14]. However, Davies et al. reported a postmenopausal case that showed exacerbation of adenomyosis while receiving tibolone [15].

Our patient had no known history of endometriosis and her symptoms began after she had received tibolone for hormonal replacement; the adnexal mass was determined after the treatment. There is restricted data in the literature about tibolone use and recurrence or de novo formation of endometriosis. Most report the beneficial effect of the drug for treatment of endometriosis [16] and its safety for treatment of residual endometriosis after menopause [17].

Exogenous estrogen supplement therapy and endogenous production of estrogens by conversion of androgens are blamed for the proliferation of endometrial lesions during the postmenopausal period. Endometriotic lesions contain estrogen and aromatase receptors.

Aromatase is an enzyme that acts as a catalyzer in conversion of androgens to estrogens [18]. The presence of aromatase receptors may explain the stimulation of the growth of endometriotic lesions by local estrogen produced through conversion from androgens in patients who have postmenopausal endometriosis without any estrogen use. In general, postmenopausal endometriosis is considered as recurrence of the previous disease. Goodman et al. [7] also proposed that endometrial metaplasia may develop under the influence of estrogen in spite of the concomitant use of progestogen. All of these hypotheses may explain the development of an endometriotic cyst during the menopausal period in patients without a previous history of endometriosis. Moreover, a series of 123 women with endometriosis who had definitive surgery (total abdominal hysterectomy with bilateral salpingooophorectomy) were followed-up to evaluate the effect of HRT regimens (estrogen only, cyclic estrogen/progestin, continuous combined estrogen/progestin) and no HRT on disease recurrence [19]. There was only one case $(2 \%)$ of recurrent endometriosis in the estrogen-only group.

The etiology and pathophysiology of endometriosis is not well understood or well documented. Furthermore postmenopausal development of endometriosis still remains a mystery as in some cases it occurs with HRT mostly as a recurrent disease or sometimes as a de nova formation and rarely without any exogenous hormone treatment. Investigation of large series is required for a better understanding of this condition. In conclusion, endometriosis should be considered in postmenopausal women who present with pelvic pain and adnexal mass while receiving HRT. 


\section{References}

1. Crosignani P, Olive D, Bergqvist A, Luciano A (2006) Advances in the management of endometriosis: an update for clinicians. Human Reprod Update 12(2):179-189

2. Barbieri RL (1990) Etiology and epidemiology of endometriosis. Am J Obstet Gynecol 162:565-567

3. Punnonen R, Klemi PJ, Nikkanen V (1980) Postmenopausal endometriosis. Eur J Obstet Gynecol Reprod Biol 11(3):195-200

4. Kempers RD, Dockerty MB, Hunt AB, Symmonds RE (1960) Significant postmenopausal endometriosis. Surg Gynecol Obstet 111:348-356

5. Lam AM, French M, Charnock FM (1992) Bilateral ureteric obstruction due to recurrent endometriosis associated with hormone replacement therapy. Aust NZ J Obstet Gynaecol 32:83-84

6. Deval B, Rafii A, Dachez MF, Kermanash R, Levardon M (2002) Sigmoid endometriosis in a post menopausal woman. Am J Obstet Gynecol 187:1723-1725

7. Goodman HM, Kredentser D, Deligdisch L (1989) Postmenopausal endometriosis associated with hormone replacement therapy. A case report. J Reprod Med 34(3):231-233

8. Goh JT, Hall BA (1992) Postmenopausal endometrioma and hormonal replacement therapy. Aust NZ J Obstet Gynaecol 32 (4):384-385

9. Bellina JH, Schenck D (2000) Large postmenopausal ovarian endometrioma. Obstet Gynecol 96:846

10. Goumenou AG, Chow C, Taylor A, Magos A (2003) Endometriosis arising during estrogen and testosterone treatment 17 years after abdominal hysterectomy: a case report. Maturitas 46(3):239-241
11. Choi SW, Lee HN, Kang SJ, Kim HO (1999) A case of cutaneous endometriosis developed in postmenopausal woman receiving hormonal replacement. J Am Acad Dermatol 41(2 Pt 2):327-329

12. Genazzani AR, Benedek-Jaszmann LJ, Hart DM, Andolsek L, Kicovic POM, Tax L (1991) Org OD 14 and the endometrium. Maturitas 13:243-251

13. Rymer JM (1998) The effects of tibolone. Gynecol Endocrinol 12 (3):213-220

14. Henderson AF, Studd JWW, Watson N (1990) A retrospective study of oestrogen replacement therapy following hysterectomy for the treatment of endometriosis. In: Shaw BW (ed) Advances in reproductive endocrinology. I. Endometriosis. Parthenon, Carnforth, UK, pp 131

15. Davies AP, Oram D (1994) Exacerbation of adenomyosis in a postmenopausal woman taking tibolone associated with an elevation in serum CA 125. Br J Obstet Gynaecol 101:632-633

16. Lindsay PC, Shaw RW, Bennink HJ, Kicovic P (1996) The effect of add-back treatment with tibolone (Livial) on patients treated with the gonadotropin-releasing hormone agonist triptorelin (decapeptyl). Fertil Steril 65:342-348

17. Fedele L, Bianchi, Raffaelli R, Zanconato G (1999) Comparison of transdermal estradiol and tibolone for the treatment of oophorectomized women with deep residual endometriosis. Maturitas 32:189-193

18. Kitawaki J, Kado N, Ishihara H, Koshiba H, Kitaoka Y, Honjo H (2002) Endometriosis: the pathophysiology as an estrogendependent disease. J Steroid Biochem Mol Biol 83(1-5):149-155

19. Rattanachaiyanont M, Tanmahasamut P, Angsuwatthana S, Techatraisak K, Inthawiwat S, Leerasiri P (2003) Hormonal replacement therapy in surgical menopause with underlying endometriosis. J Med Assoc Thai 86(8):702-707 